\title{
Social and economic implications of nutrition surveys and other epidemiological evidence
}

\author{
By W. T. C. Berry, ${ }_{4}$ Church Farm, Colney, Norwich
}

\section{Introduction}

The surveys and other evidence which are drawn upon are part of the general scheme of surveillance of nutrition in Britain. Before 1968 this was by means of running indices (Berry \& Hollingsworth, 1963), helped out by small-scale surveys and other work aimed to throw light on specific points. In I968-197I, under the aegis of the Committee on Medical Aspects of Food Policy, more detailed surveys were made of old people, pregnant women, pre-school children and schoolchildren of various ages, totalling about $4000-4500$ people, the aim being to establish a baseline. In I97I an expert Subcommittee on Nutritional Surveillance was set up to advise in the first place on what measures were needed to monitor the effects of various changes in welfare and school milk, and meals, and the result of their advice has been a return largely to a system of running indices, better than before.

\section{The running indices : $1955^{-7} \mathrm{I}$}

Expressed in terms of quantities of foods per unit of energy content (the most informative way to present the data) the National Food Survey (NFS) shows increases in the consumption of the main foods of animal origin in all the major income groups, which were not so marked in the lower income groups; for example the recorded consumption of meat rose by $24 \%$ in income group $\mathrm{A}$, $18 \%$ in $\mathrm{B}, 17 \%$ in $\mathrm{C}$ and only $13 \%$ in D (J. W. Marr \& W. T. C. Berry, to be published). Among other indices of prosperity, the amount of money spent on food, expressed as a proportion of expenditure on all goods and services, fell over-all by about $46 \%$ (National Income and Expenditure, r 973).

The perinatal death rate fell, albeit not necessarily because of nutritional factors operating either currently or cumulatively over the preceding period of prosperity and the growth rates of children generally accelerated (Department of Health $\&$ Social Security, 1973). The existence of social gradients in both perinatal mortality and in stature of children at given ages suggests that the relevant potentials of both women and children have not yet been fully realized, though the reasons are not necessarily nutritional. Over this same period there have been substantial increases in the proportion of fat in the diet (Marr, I973; National Food Survey Committee, I973), a rise in deaths from coronary disease and, probably, an increase in the incidence of obesity and of diabetes due to obesity. Though we probably have not yet eliminated from Britain the forms of malnutrition arising out of want, there are already arising the diseases of excess. 


\section{Cross-sectional studies : (1) Methodological}

Running indices reflect change, but not where from or where to in terms of the state of nutrition of the subject. For that, cross-sectional surveys are needed, ideally on nationally representative samples, and covering all aspects of the environment that touch upon nutrition. That comprehensiveness is desirable is illustrated by the following example, taken from our 1968 survey of the elderly (Department of Health \& Social Security, 1972). The survey shows that the food pattern of the elderly is not very different from that of the rest of the nation; they eat less total food, but their energy expenditure and hence their requirement of energy is less. Nevertheless, there is an economic gradient in energy consumption (Table I) which has to be explained. As group a consisted mainly of people who lived with their relations and hence were probably not underfed, the most likely explanation of their low energy consumption was that in many instances they were too decrepit or ill to fend for themselves, and because of their frailness it is to be expected that their energy output and intake was below average. The important issue is the difference between groups 2 and 3 , because it may indicate that the Supplementary Benefit was insufficient. When those in group 3 who were still working, and expending more energy at work, were excluded (group $3^{\mathrm{A}}$ ), the difference from group 2 was reduced (Table I). The difference between groups 2 and 3 was reduced further by expressing the results in terms of energy expenditure per unit of body-weight (Table 2). The groups did not differ with respect to Quetelet's Index, but men from group 3 tended to be thinner in terms of skinfolds $(P<O \cdot I)$. More detailed investigations were made of every man consuming less than $6280 \mathrm{~kJ}$ (1500 kcal) daily and every woman consuming less than $5020 \mathrm{~kJ}$ (1200 kcal) (about $10 \%$ of the sample). Among these we identified a group of people either biologically (and often chronologically) very old, or suffering from some disease which hampered their preparation of food, such as dimness of vision or arthritis of the hands. Some of these showed biochemical as well as anthropometric and dietary evidence of undernutrition. Such people might stay on in their own homes longer than was good for their health because they did not care for the alternatives, while others in a similar situation but with more money might be able to hire domestic help or go to live in some hotel or nursing home where they would be looked after: the problem is one for local authorities.

The lessons on methodology are: first, the comprehensive nature of the tests that have to be included in surveys, if the causes of malnutrition are multifactorial; and secondly, the importance of non-nutritional disease in causing malnutrition in old people.

\section{Cross-sectional studies : (2) Other vulnerable groups}

When dealing with a form of malnutrition which has unequivocal manifestations it is not easy to determine its social and economic causes. When the manifestation is itself of uncertain nutritional significance it is even harder: this is the situation with the gradients in perinatal mortality rate and the growth rate of children, associated with social or economic conditions, or both. A further uncertainty is the extent to 


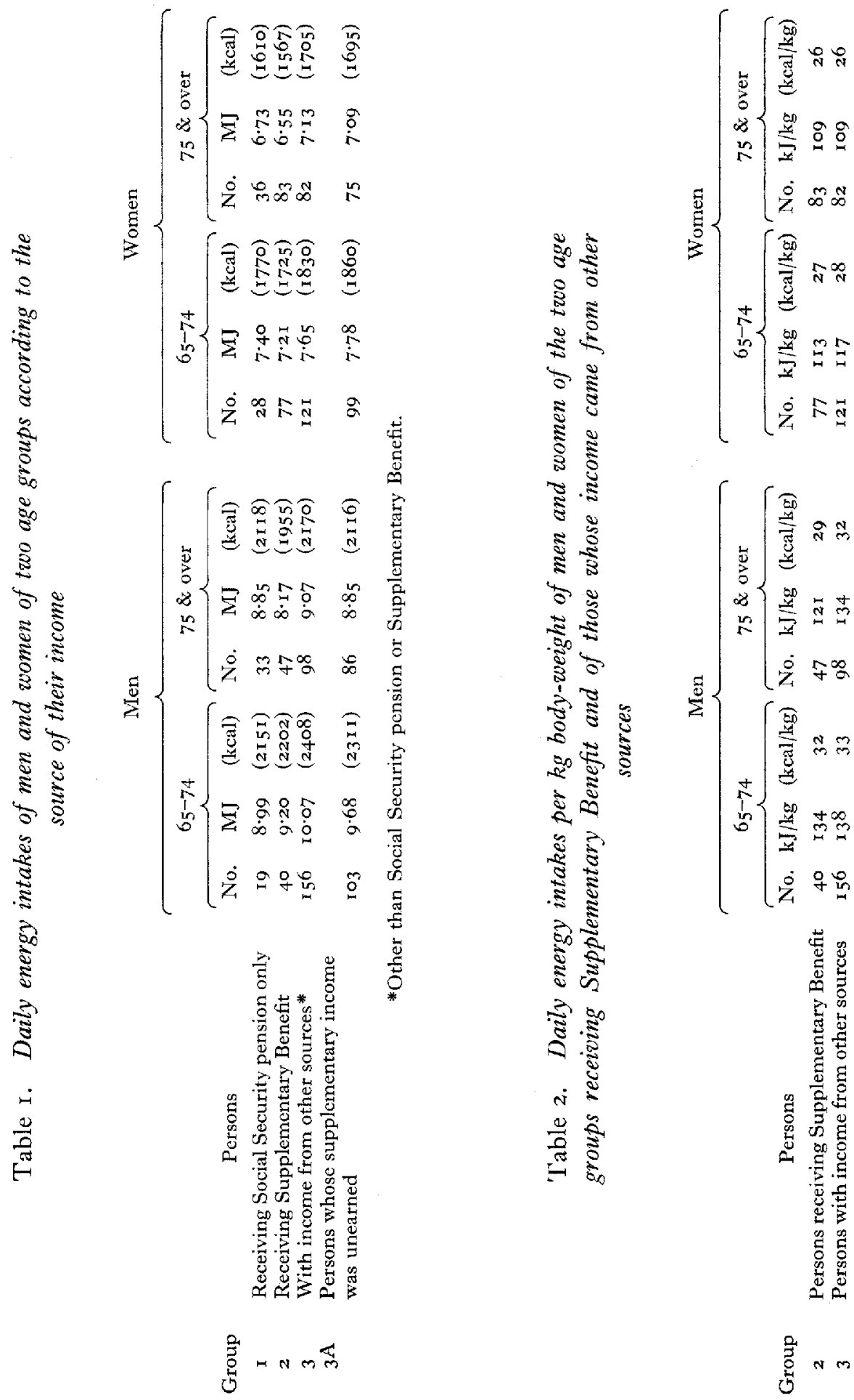


which the differences observed reflect some factor operating at the time or something which occurred earlier in life and set an upper limit to the rate of growth and development. For example, after the Government cancelled secondary school milk in 1968 we watched for possible effects on growth rate. Up till then about $60 \%$ of the milk was being taken up, and it was available for the $200 \mathrm{~d}$ only of the school year, but as a nutritional supplement this was by no means negligible. Growth rates in Scotland (by far our best source of data) remained remarkably steady (Scottish Home \& Health Department, 1972) with no indication of any widening in the gap between social classes (Fig. I).
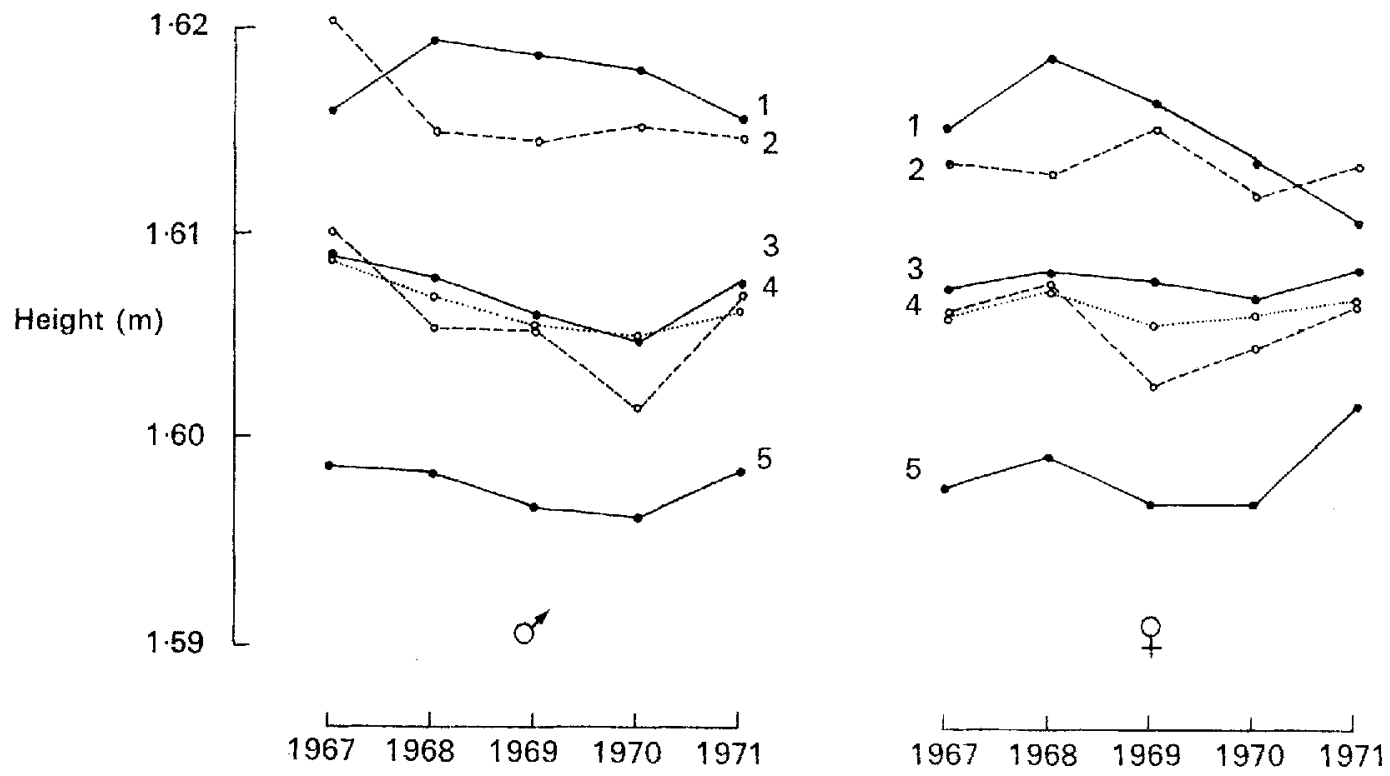

Fig. 1. Mean heights (10\% sample) of Scottish boys and girls aged 14 years, for the years 1967-1971, grouped in Registrar General's social classes $1-5.0 \ldots \ldots$, mean for all classes. (Figures by courtesy of the Scottish Home \& Health Department).

Socio-economic differences in growth rate may partly reflect a carry-over from changes occurring during pregnancy. We found in our surveys of 400 pregnant women (from thirty-nine areas scattered over Britain) that maternal height, social class, nutrient intake and several other factors were associated (Department of

Table 3. Birth weight of children and percentage of energy derived from protein in their mothers' diets

\begin{tabular}{|c|c|c|c|c|c|c|c|}
\hline \multicolumn{2}{|c|}{ Birth weight } & & \multirow{2}{*}{$\begin{array}{l}\text { Average \% of } \\
\text { energy from } \\
\text { protein }\end{array}$} & \multirow[b]{2}{*}{$\mathrm{SE}$} & \multicolumn{3}{|c|}{ Daily energy intake } \\
\hline (lb) & $(\mathrm{kg})$ & No. & & & $\mathrm{MJ}$ & (kcal) & SE \\
\hline $5 \mathrm{lb} 8 \mathrm{oz}$ and under & under $z \cdot 5$ & 9 & $12 \cdot 3$ & 0.77 & $8.8 \mathrm{I}$ & $(2108)$ & 0.71 \\
\hline $5 \mathrm{lb} 9 \mathrm{oz}-6$ lb I $5 \mathrm{oz}$ & $2 \cdot 5-3 \cdot 2$ & 80 & $12 \cdot 66$ & 0.20 & 9.04 & $(2163)$ & 0.23 \\
\hline $7 \mathrm{lb}-7 \mathrm{lb} \times 5 \mathrm{oz}$ & $3 \cdot 2-3 \cdot 6$ & I 37 & 13.47 & 0.19 & 9.00 & (2I 54) & 0.19 \\
\hline $8 \mathrm{lb}-8 \mathrm{lb}$ I $5 \mathrm{oz}$ & $3 \cdot 6-4 \cdot 1$ & 89 & $13 \cdot 36$ & 0.24 & 8.99 & $(2 I 5 I)$ & 0.19 \\
\hline $9 \mathrm{lb}-9 \mathrm{lb} \times 5 \mathrm{oz}$ & $4^{\cdot I}-4 \cdot 5$ & 36 & 13.71 & 0.49 & $8 \cdot 70$ & $(2082)$ & 0.36 \\
\hline ro $\mathrm{lb}$ and over & over 4.5 & 8 & 14.16 & 0.57 & $8: 70$ & $(2082)$ & 0.82 \\
\hline
\end{tabular}


Health \& Social Security, I968). There was, for example, a relationship between birth weight and maternal consumption of protein (Table 3 ) (which should be regarded here mainly as an indicator of the quality of the diet) and between birth weight and maternal height. A statistically significant negative association was found between birth weight and the mother's habit of smoking during pregnancy. When the relationship between maternal milk consumption and birth weight is compared in those who did and did not smoke during pregnancy, the effect of milk on birth weight virtually disappears (Table 4 ).

Table 4. Effect of mother smoking during pregnancy on mean consumption of mother's milk $(g / d)$ by babies of various birth weights

\begin{tabular}{|c|c|c|c|c|c|c|c|c|}
\hline & \multicolumn{8}{|c|}{ Birth weight of baby $(\mathrm{kg})$} \\
\hline & \multicolumn{2}{|c|}{$\overbrace{}^{\text {under } 2.5}$} & \multicolumn{2}{|c|}{$\underbrace{2 \cdot 5-3 \cdot 2}$} & \multicolumn{2}{|c|}{$3 \cdot 2-3 \cdot 6$} & \multicolumn{2}{|c|}{4.0 and over } \\
\hline & No. & $\begin{array}{l}\text { Milk } \\
\text { intake }\end{array}$ & No. & $\begin{array}{l}\text { Milk } \\
\text { intake }\end{array}$ & No. & $\begin{array}{l}\text { Milk } \\
\text { intake }\end{array}$ & No. & $\begin{array}{l}\text { Milk } \\
\text { intake }\end{array}$ \\
\hline Mather smoked during pregnancy & 3 & 295 & 27 & 420 & 52 & 360 & 8 & ${ }_{3}^{8} 8_{3}$ \\
\hline $\begin{array}{l}\text { Mother did not smoke during } \\
\text { pregnancy }\end{array}$ & 6 & 403 & 50 & 468 & 77 & 490 & 34 & 468 \\
\hline
\end{tabular}

The pre-school survey of I968 (Department of Health \& Social Security, to be published) was on larger numbers ( 1300 children in four age groups) but the results were inconclusive. There were some indications of associations between milk consumption and stature at ages 2 and 3 but not at age 4 (Fig. 2 ), between income group and milk consumption, between parental height and child's height, and so on. Very few of the relationships were statistically significant, partly because recorded height at this age is subject to fairly large variations from the mode. However, the same general association between 'goodness' and 'badness' of socio-economic circumstances which was apparent in other groups existed.

\section{The current period of running indices}

The Subcommittee on Nutritional Surveillance has initiated growth studies of schoolchildren on a sounder scientific basis than hitherto (Department of Health \& Social Security, I973). A study of the growth of preschool children has been started, and various steps have been taken to improve the sensitivity of other running indices. Any adverse changes which appear to have arisen as a result of changes in our food situation may require confirmation in a controlled feeding test. One such pilot test has already been initiated by the Subcommittee.

As we have no satisfactory running index of the elderly, the I 968 survey (Department of Health \& Social Security, 1972) was repeated recently on those of the previous study who could be traced, and a fresh cross-sectional study is currently in progress, making use of our previous experience and of newly-developed methods of nutritional assessment of which we were only able to make limited use in 1968 .

In conclusion, it has to be admitted that just as few if any socio-economic studies have included evidence that the nutritionist would regard as adequate, the reverse 


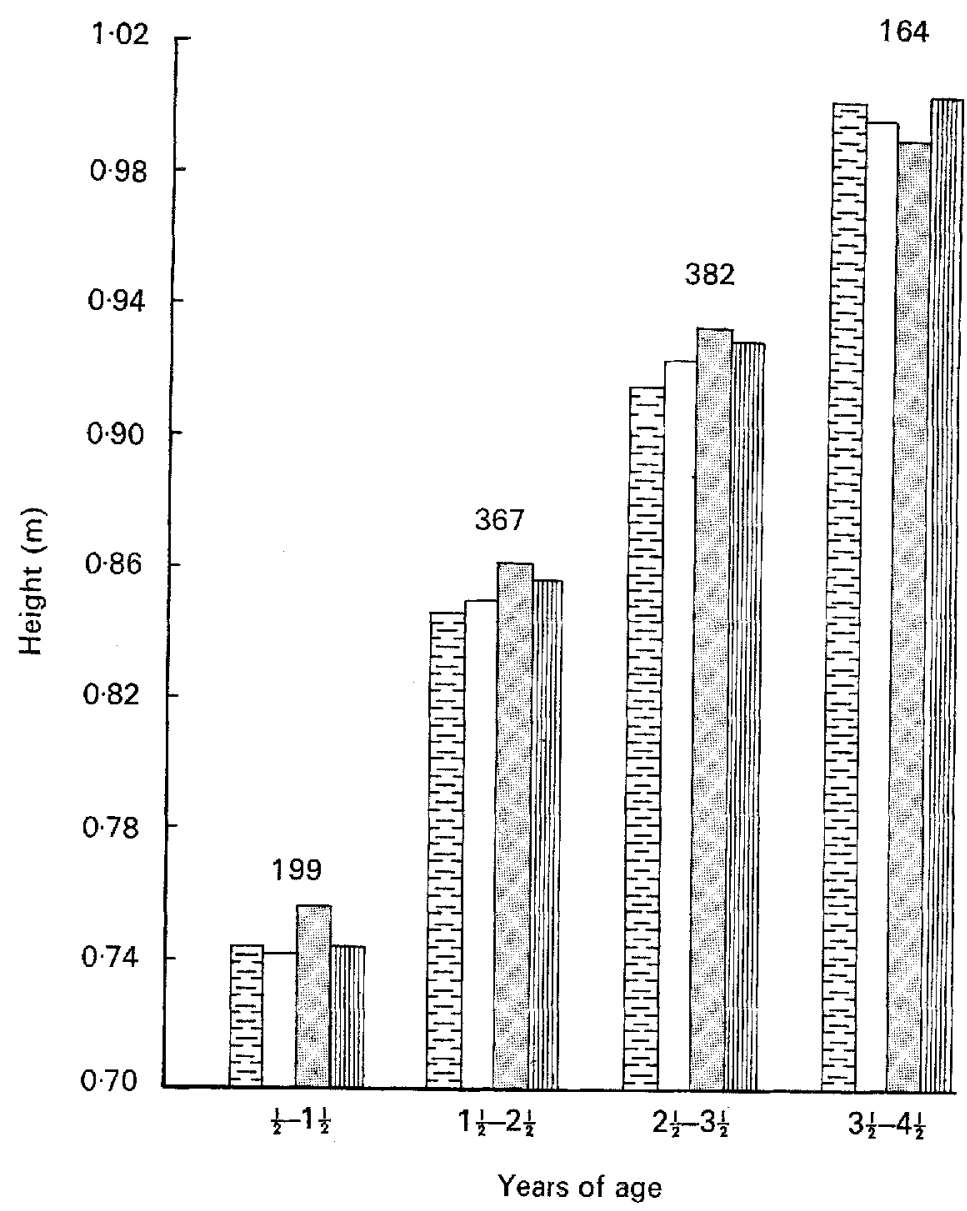

Fig. 2. Relationship between milk consumption and height of children $\frac{1}{2}-4 \frac{1}{2}$ years old in 1968 . Approximate consumption of milk $(\mathrm{g} / \mathrm{d})$ : 圈, 200; $\square, 320$, 4ro; 西, 600. Figure over each column is total number of observations. From Department of Health \& Social Security (to be published).

is also true. Perhaps we are all of us too keen to secure what we regard as the important objectives of our different surveys and refuse too steadfastly to include additional questions or manoeuvres which might exhaust our participants' patience and so prejudice our aims. It could well be that each must yield somewhat, and formulate what they consider to be the essential minimum of information needed to obtain the maximum of value out of each other's investigations.

\section{REFERENCES}

Berry, W. T. C. \& Hollingsworth, D. F. (1963). Proc. Nutr. Soc. 22, 48.

Department of Health \& Social Security (1968). A survey of the diets of women in the 6th-7th month of pregnancy, in $1967-8$.

Department of Health \& Social Security (1972). Rep Hlth \& Soc. Subj., Lond. No. 3. 
Department of Health \& Social Security (1973). Rep. Hlth E Soc. Subj., Lond. No. 6.

Marr, J. W. (1973). Health Trends 5, 37.

National Food Survey Committee (1973). Household Food Consumption and Expenditure, 1970-7I, London: II.M. Stationery Office.

National Income and Expenditure (1973). Report. London: H.M. Stationery Office.

Scottish Home \& Health Department (1972). Research $\mathscr{S}^{\circ}$ Intelligence Unit Information Sheet No. 2. 